\title{
WHY DID ACT 1 OF FROM THE HOUSE OF THE DEAD END WITH THE SKURATOV THEME?
}

Skuratov is an important character in Janáček's final opera. He is one of the few who have something to do in each act. His main appearance is in Act 2, when he tells his long story about how he courted the German washerwoman Lujza and ended up shooting her elderly husband, for which crime he has been sent to this Siberian prison. He is introduced in Act 1. We see and hear him first in the middle of the act, where he alternates his merry song (Já mladá na hodech byla) with the sad song of the prisoners as they go off to work (Neuvidi oko již těch krajü). Straight afterwards he has an argument with Luka, and then goes on to describe his earlier life. Upset by these memories, he begins a furious dance, at the end of which he falls down exhausted. And that is the last we see of him until Act 2.

Janáček gives him a very distinct and memorable theme: a tune made up of just three notes and a falling arpeggio in the bass (Ex. 1).

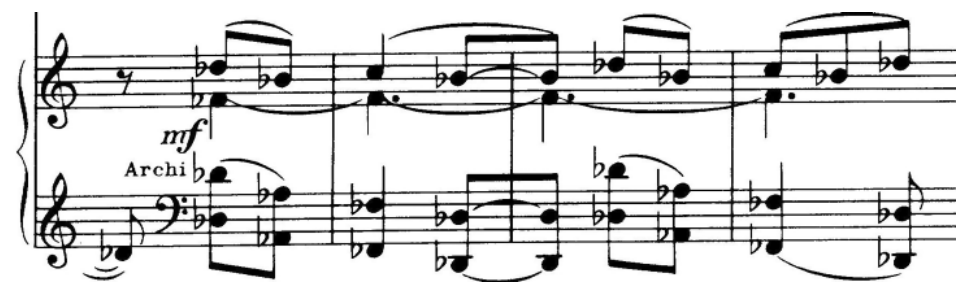

Ex. 1 Skuratov theme (S)

His song Já mladá na hodech byla has its own tune but as soon as the Prisoners have gone off to work, his distinct theme is heard again, sometimes both tune and bass, sometimes just the bass, as a background to his argument with Luka (VS, pp. 34-5). ${ }^{1}$ The theme is also heard when he recalls his former life as a shoemaker, how he misses Moscow and how his life has fallen apart (VS 36-8 from Sbohem

$1 \quad$ VS $=$ references to the Universal Edition piano-vocal score, Vienna 1930 and subsequent reprints. 
Moskvo). When he dances, the bass of the Skuratov theme is heard sometimes low, sometimes high (VS 39-40).

What is odd - the subject of this short enquiry - is that in the last few minutes of the act, when Luka gets to the end of his horrifying narration with the words Myslím, že umirám [I though that I was dying], the Skuratov theme is heard once again. The Elderly Prisoner asks his naive question "A umřels?" [And did you?] and against Luka's "Hlupáku!" [Idiot!] (the last words of Act 1), the Skuratov theme is heard in the orchestra and is presented in different variations until the end of the act (VS 54-55).

There seems to be no reason for this since up until now the theme has been associated only with Skuratov, his personal leitmotif. No wonder commentators have found this puzzling. If there is a rational explanation for this - one doesn't always expect rational explanations with Janáček - it may lie in the thematic evolution of the act. I shall examine just two themes: the Skuratov theme (S) and one - the most important theme in the act - that I will call the Motto theme (M, see Ex. 2).

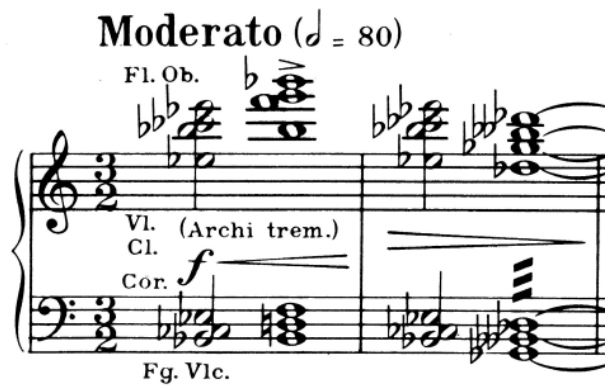

Ex. 2 Motto theme (M)

Anyone who knows the opera will be familiar with this motto theme: it comes straight after the overture as the curtain goes up on the action. It is heard many times throughout the act, for instance in a more continuous, developed form (VS 30). Table 1 provides a brief summary of the events of Act 1 as we know it today. I have included the symbols $\mathrm{M}$ and $\mathrm{S}$ to show the main occurrences of these two themes

\section{Table 1: Action in Act 1 (final version)}

main events

1 Prisoners get up, wash, eat, argue

2 Petrovič arrives, is interrogated, taken off and beaten

3 The convicts tease an eagle with a broken wing use of $M$ or $S$

$\mathrm{M}$

$\mathrm{M}$

$\mathrm{M}$

$\mathrm{M}$ 


$\begin{array}{lll} & \text { The guards end this } & \mathrm{M} \\ 4 & \text { Prisoners go off to work: sad and merry songs } & \mathrm{M} \\ 5 & \text { Skuratov argues with Luka } & \mathrm{S} \\ & \text { Skuratov tells about his past } & \mathrm{S} \\ & \text { Skuratov's dance } & \mathrm{S} \\ 6 & \text { Luka's story of the old man } & \mathrm{M} \\ & \text { How Luka knifed the major } & \mathrm{M} \\ & \text { How Luka was beaten } & \mathrm{M} \\ 7 & \text { Orchestral epilogue } & \text { S developed }\end{array}$

As is clear from Table 1, all sections apart from no. 5 (the Skuratov section) and no. 7 (the orchestral epilogue) include and often climax with the motto theme. In an opera built up like this of almost random incidents with few causal or even chronological connections, music plays an important part in unifying the act. The motto theme has an essential structural and associative function. The association of pain, both physical and mental, is clear from every use of the motto theme, for instance in Luka's narrative when it occurs at the climaxes: when he describes how he stabbed his commanding officer, and how he was flogged for doing so. So it seems all the more odd that Act 1 doesn't end with some sort of orchestral variation on the motto theme. Does a study of the earlier stages of work help to explain this?

One of the big surprises is how late the motto theme occurred to Janáček when composing this act. As usual he wrote the act roughly three times. We are exceptionally lucky that so much of the earlier sketch material survives. Table 2 gives a basic description of the three versions.

\section{Table 2: Janáčeks writing of Act 1 of $Z$ mrtvého domu}

Version I

Version II (new pagination) 147

Version III (same pagination) ${ }^{2} \quad 138$

125 total no. of pages missing pages

28

10 (7 reused in Version III)

In the sketches the motto theme is found for the first time on p. 123 of Version II at the first climax of the Luka story (see Table 1, no. 6). This is very late, just $16 \%$ before the end of the act. It was not there at the beginning, it was not connected with the torturing of Petrovič and the torturing of the eagle. It was not there for

2 Version III has the same pagination as Version II but includes many later additions. It was numbered to 151, but some pages omitted. The result was then copied out by Václav Sedláček under Janáček's supervision and with his additions to serve as the fair copy of the opera (BmJA, A 11.489). Version III can be found in BmJA, A 7446, Versions I and II in BmJA, A 33.746. 
the sad songs. Ex. 3 show the very first occurrence of the theme in the sketches. ${ }^{3}$ At Luka's words "Tak i propadla moja golova!'[And so my head dropped off], in the second bar, it is clear how Janáček has added the theme in the flutes (Ex. 3). For those unfamiliar with Janáček's manuscript I provide a transcription (Ex. 4). ${ }^{4}$

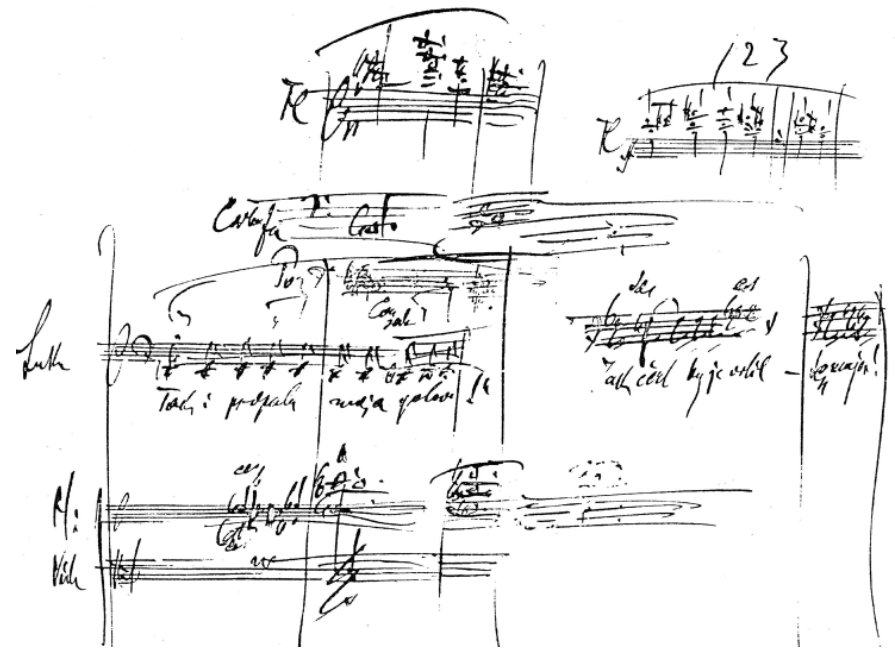

Ex. 3 ZMD, Version $\mathrm{II}^{1 / 2}$, first occurence of $\mathrm{M}$
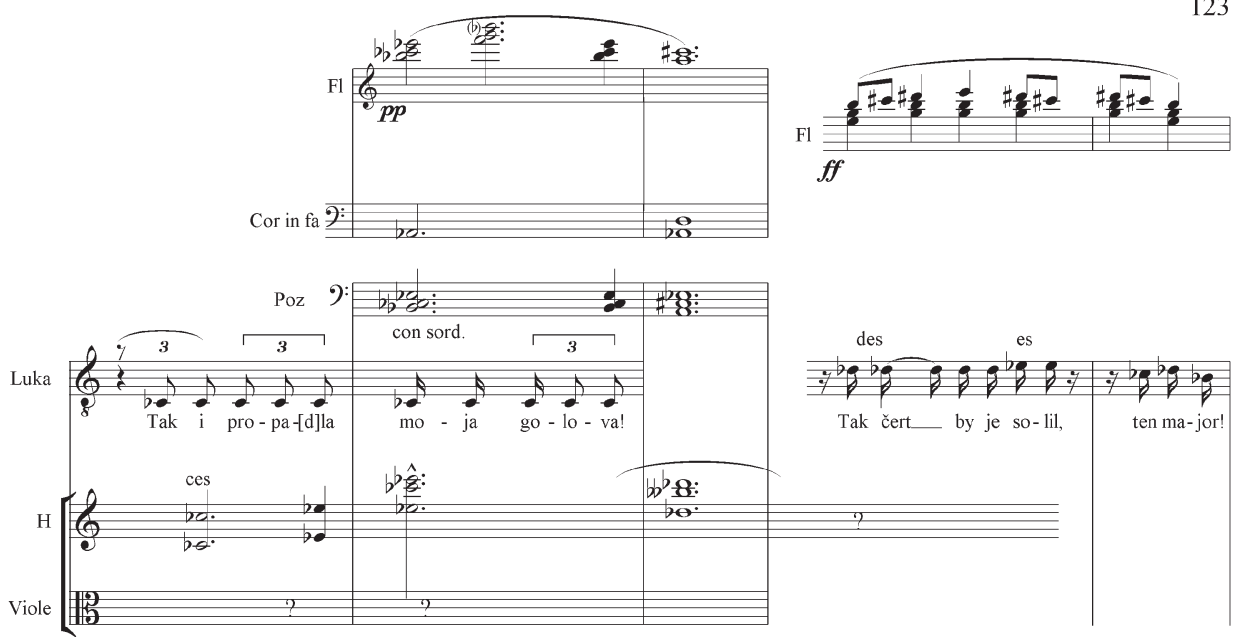

Ex. 4 Transcription of Ex. 3

3 All examples from Janáček sketches reproduced with kind permission from the Janáček archive of the Moravian Museum, Brno.

4 I am very grateful to Mark Audus, who has transcribed this and all subsequent transcriptions in this article. 
This is a single, isolated use and one that indeed may have been added later - a sudden idea as Janáček revised the act. And he must then have suddenly sensed the possibilities of the theme for, exceptionally, he did not then make a final version, but added an extra partial version, where the theme was used as often as possible - more frequently in fact than in its final state. It was in this version that Janáček used it to punctuate the three climaxes of Luka's narration, and the Prisoners' chorus and so on. And in Version III Janáček opened the act with this theme and used it to climax the first section.

The other, main unifying theme of the act, the Skuratov theme, also appears for the first time in Version II. The first use of the theme in Version II, however, is a prototype of its present form, see Janáček's original autograph (Ex. 5) and Mark Audus's transcription (Ex. 6). This prototype has the same rhythm and the same restricted selection of notes as Ex. 1, but it lacks the descending bass. It is a very sombre-sounding theme on low strings. After two bars the voice joins it. Incidentally, Janáček, never got Skuratov's name right: he called him "Skutarov" throughout the opera.

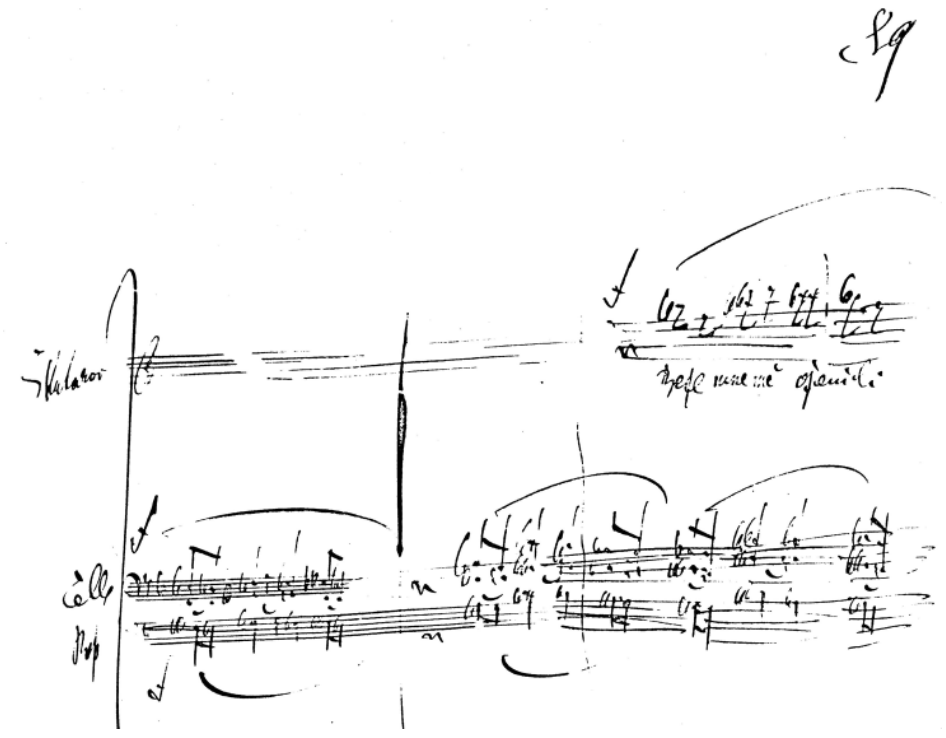

Ex. 5 Version II, prototype of S

In the final version the Skuratov theme provides material for the entire Skuratov section (no. 5) in the middle of Act 1, but in Version II it disappeared after a couple of pages to make way for a many other themes. This is very typical of Janáček's sketches. Earlier versions have many different themes; later ones concentrate on just a few, adding variations and developments. The extra stage of Version II saw the great expansion of variations of the Skuratov theme to fill up the entire episode. It was only halfway through this set of variations, however, on 


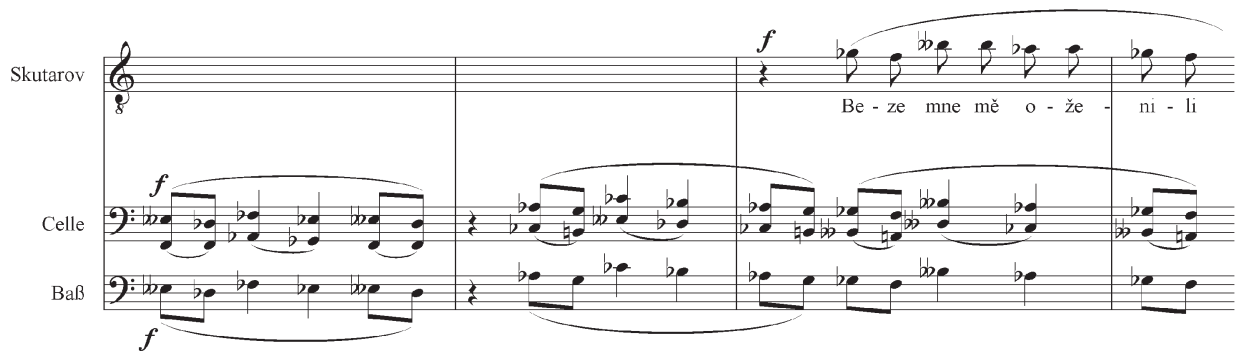

Ex. 6 transcription of Ex. 5

p. 102, that the present dual theme (restricted tune, arpeggio bass) was discovered (Ex. 7).

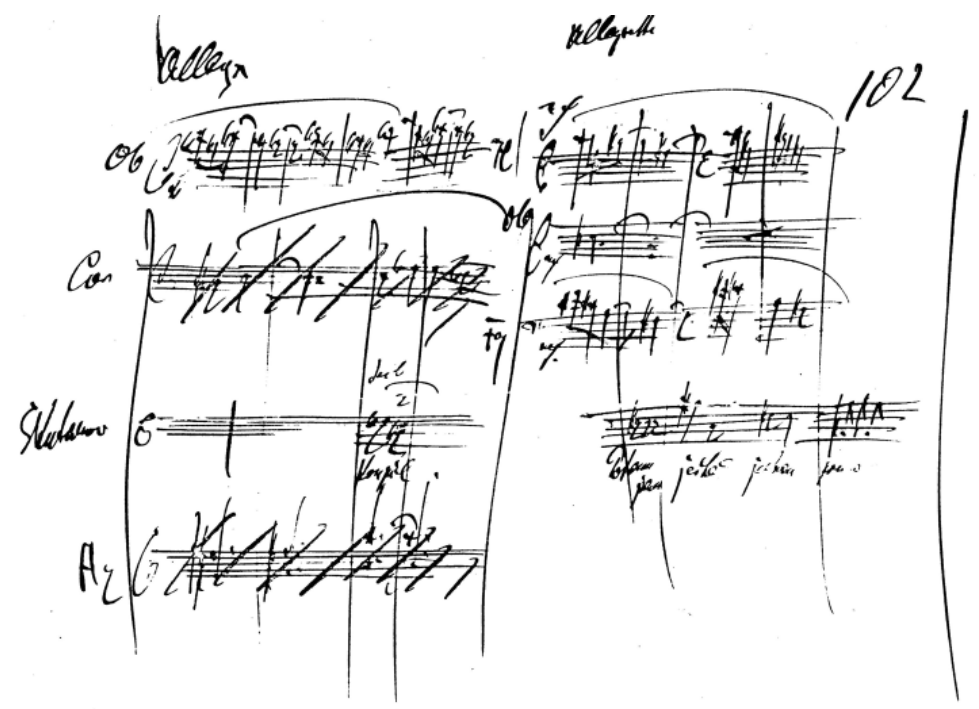

Ex. 7 Version $2^{1 / 2}$, first occurence of dual version of $S$

On p. 102 Janáček suddenly crossed out the previous accompaniment - see cor (horn) and $\mathrm{H} 2$ (second violins) - and then halfway through the page boldly wrote a bassoon part $(\mathrm{Fg})$ with the descending theme. But even at this late stage Janáček still muddled his name - still Skutarov (see Ex. 7, transcribed in Ex. 8). 

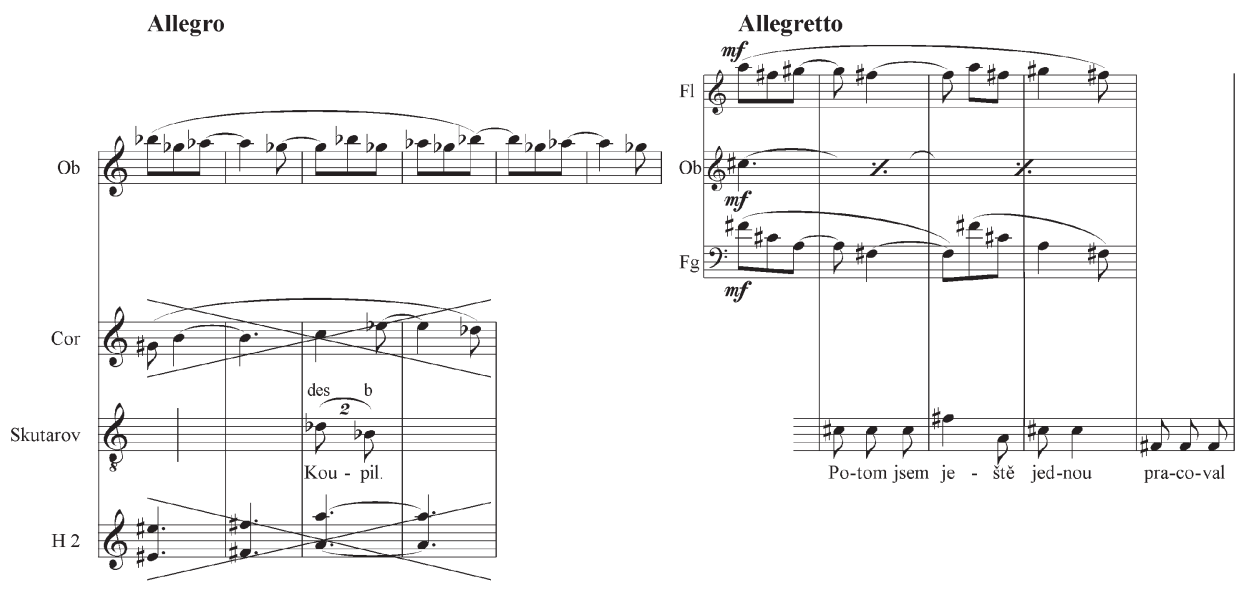

Ex. 8 transcription of Ex. 7

Let us reconsider the puzzling use of the Skuratov theme in the final section of the opera by comparing the action of the first version to that of the final version:

Table 3: Comparison of the action in final and first versions of $Z$ mrtvého domu

\section{Version III}

1 Prisoners get up, wash, eat, argue

2 Petrovič arrives, interrogated, beaten

3 The convicts tease an eagle with a broken wing; The guards end this

4

5

Skuratov argues with Luka

Skuratov tells about his past

Skuratov's dance

6 Luka's story of the old man

How Luka knifed the major

How Luka was beaten

7

Orchestral epilogue

\section{Version I}

YES

YES

YES

YES

orchestral night

scene, dawn

YES

YES

YES

In Version I the action of Act 1 was rather different. It did not begin with the Prisoners getting up but merely with the arrival of Petrovič; sections 3-5 were basically the same, but there was no Luka story and no epilogue. Instead there was an extensive night interlude, following the sad chorus. And there the function 
of the chorus was quite different; today it is a going-to-work chorus. But it used to be a going-to-sleep chorus, and thus the wordless, very soft version was not, as now, a faraway version, but a very sleepy version, just before an orchestral interlude with stage directions to indicate night and then dawn.

This night scene disappeared by Version II, where Luka's narrative was added; but the orchestral epilogue was still not in place. By the extra half-version Luka's narration ended appropriately with the motto theme. Ex. 9 shows the original ending on p. 145 with the motto theme in bars 2 , see $\mathrm{H}$ (violins) on the lowest stave.

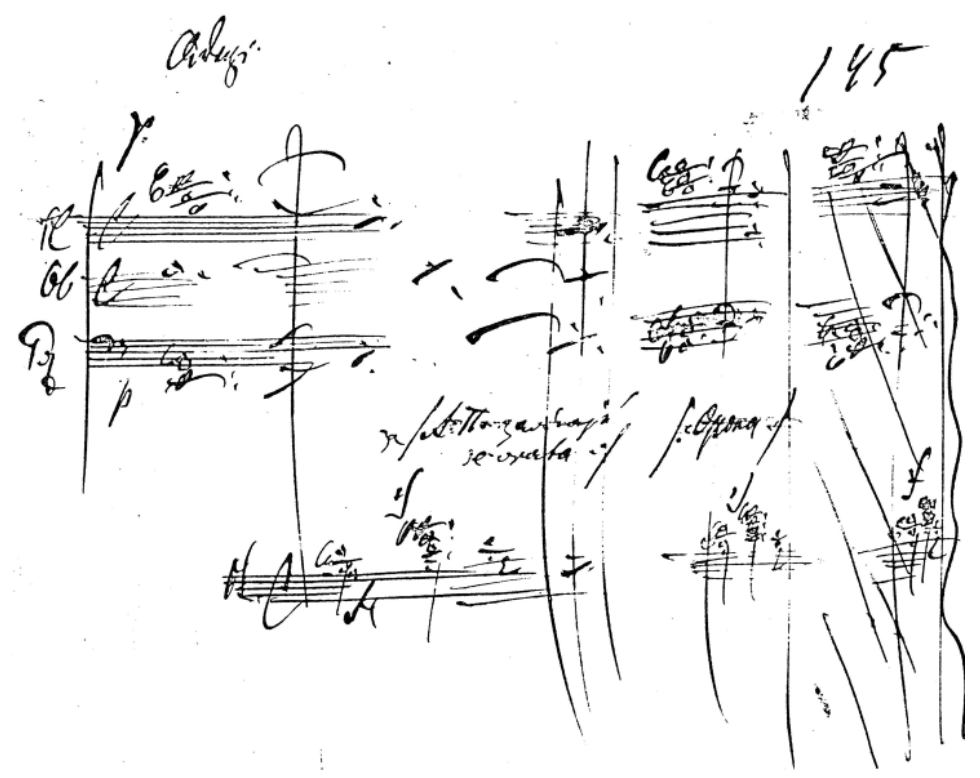

Ex. 9 Version II, original ending with $M$

The gates close behind Petrovič, who has just been brought back in a semi-conscious state - note the stage direction "za A.P zaviraji se vrata" [The gates close after Alexandr Petrovič (Janáček always used a Russian P for Petrovič)]. You can also see the word "opona" (curtain), then more motto theme on the violins and finally a wavy, vertical line, which was Janáček's way of indicating the end of the act. But it is also clear that last two bars have been crossed out. It seems that Janáček was not satisfied with this ending and, exceptionally, turned the sheet over and on the back wrote a continuation (Ex. 10, facsimile in Ex. 11). 
There is a naive question from the Elderly Prisoner ("a umrels?"), heard over the Skuratov theme, which is then developed to bring the act to an end.

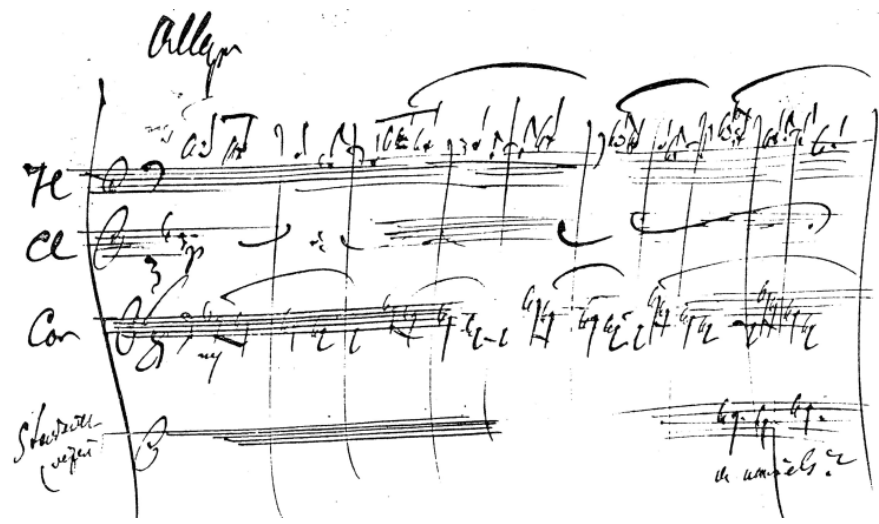

Ex. 10 back of previous page, with introduction of $S$

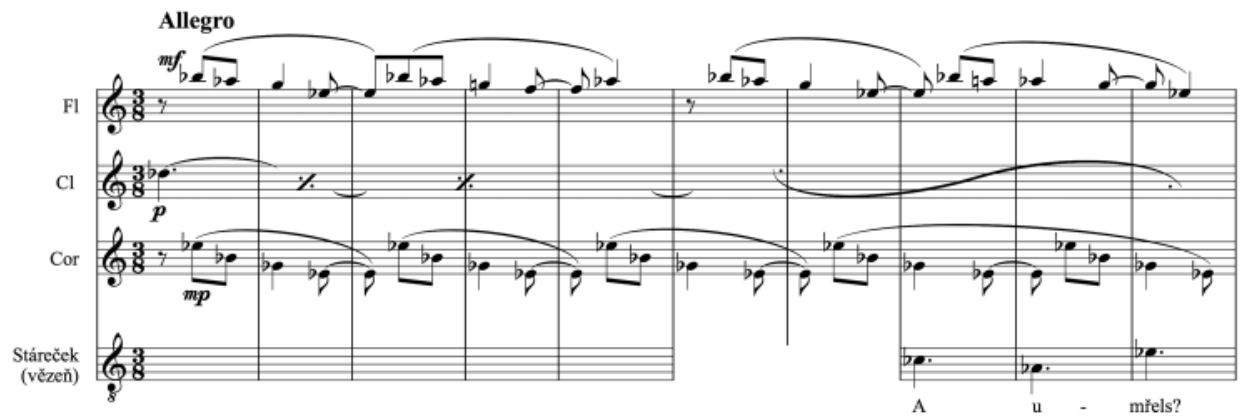

Ex. 11 transcription of Ex. 10

The sketches don't of course say why Janáček used the Skuratov theme, which is considered so inappropriate here. So instead I offer two explanations:

The first is that Janáček wrote used Skuratov music to introduce "a umřels?" rather as if he associated the Skuratov music with a simple-minded character - in this case the Elderly Prisoner rather than Skuratov. And then he brought the act to an end with this music. 
Alternatively it does seem significant to me that the Skuratov theme was added at a stage of work where Janáček was concerned above all with thematic unity - a stage, for instance, when he added adding all the extra recurrences of the motto theme. He abandoned a version ending logically with the motto theme, added a fresh ending based on the other main theme of the act. I can't believe that I'm the only one to find this musically and dramatically a balanced and satisfying solution.

John Tyrrell has written extensively on Janáček, most recently in his two-volume biography Janáček: Years of a Life (Faber, London, 2006-7). He is also the editor (with Charles Mackerras) of the 'Brno 1908' version of Jenifa (1996) and of From the House of the Dead (in press).

\begin{abstract}
:
Skuratov is an important character in Janáček's final opera, one of the few who have something to do in each act. What is very odd is that at the end of the act when Luka ends his horrifying story with the words 'Myslím, že umírám', the Skuratov theme is heard again. The Elderly Prisoner asks a naive question 'A umřels?' and against Luka's 'Hlupáku!' (the last words of Act 1), the Skuratov theme starts up and is heard in different variations in an extended orchestral epilogue to the act. There appears to be no reason for this. It is a theme that has been associated only with Skuratov and commentators have found this puzzling.

In order to try and solve this puzzle this paper examines the evolution of this and the other main theme (the so-called 'Motto' theme) of Act 1 during Janáček's sketching of the opera (both came very late in the compositions process). It may be that Janáček wrote used Skuratov music to introduce 'a umřels?' rather as if he associated the Skuratov music with a simple-minded character - in this case the Elderly Prisoner rather than Skuratov. And then he brought the act to an end with this music. Alternatively it seems significant that the Skuratov theme was added at a stage of work where Janáček was concerned above all with thematic unity - a stage, for instance, when he added adding all the extra recurrences of the motto theme. But he abandoned a version ending logically with the motto theme and added a fresh ending based on the other main theme of the act. Although initially puzzling it does, musically and dramatically, provide a balanced and satisfying conclusion to the this act.
\end{abstract}

\title{
Key words:
}

Janáček, opera, From the House of the Dead, sketch analysis, motivic analysis

\section{Bibliography:}

JANÁČEK, Leoš. From the House of the Dead. Piano-vocal score, Vienna: Universal Edition, 1930.

JANÁČEK, Leoš. From the House of the Dead. Versions: fair copy of the opera (BmJA, A 11.489); Versions I and II (BmJA, A 33.746); Version III (BmJA, A 7446). 